\title{
Proteomics Data Acquisition Method
}

National Cancer Institute

\section{Source}

National Cancer Institute. Proteomics Data Acquisition Method. NCI Thesaurus. Code C161784.

A method applied to a proteomics study in order to collect the experimental data. 